\title{
Editor's Message: How much interdisciplinary collaboration between the natural and social sciences is there in groundwater research?
}

\author{
Roland Barthel ${ }^{1}$ \\ Received: 23 February 2017 / Accepted: 7 June 2017 / Published online: 28 June 2017 \\ (C) Springer-Verlag GmbH Germany 2017
}

A statement in the editorial of a recently published special issue on interdisciplinarity in Nature $(2015$, p. 305) caught our attention: "To solve the grand challenges facing society - energy, water, climate, food, health scientists and social scientists must work together". We, that is the author, a hydrogeologist, and Roman Seidl, an environmental psychologist at the Department of Environmental Systems Science, Transdisciplinarity Lab, ETH Zurich, Switzerland, had previously worked together in the context of a large multidisciplinary project which had a particular focus on the integration of natural and social science questions. Whether or not the integration in that specific project had worked well would be worth a discussion of its own; however, one outcome of this endeavour was a raised interest in research collaboration across the natural-social science divide. Both being interested in water resources, we had started out by investigating collaboration at the interface between the natural and social sciences, which involved conducting a survey among hydrologists, asking them questions with regard to their views on the status and nature of such a collaboration. The link to the online survey was sent to members of the International Association of Hydrogeologists (IAH) and the International Association of Hydrological Sciences (IAHS) and a selection of 1,800 authors of articles in journals such as Water Resources Research or Water International. Some of the questions were inspired by the recently introduced concept of sociohydrology (Sivapalan et al. 2012), which is regarded by some

Roland Barthel is an associate editor of Hydrogeology Journal

Roland Barthel

roland.barthel@gvc.gu.se

1 Department of Earth Sciences, University of Gothenburg, 40530 Gothenburg, Sweden as a framework for bringing together hydrology and social sciences. The survey's results show that most hydrologists agree that collaboration with social scientists has to be intensified; however, there is no clear consensus on how this could be achieved, or how collaboration should be performed. Specifically, socio-hydrology as a young emerging, and rapidly evolving concept, seems to have the tendency to assimilate social science questions into hydrology, rather than achieving integration through explicit collaboration. The full results of this study are presented in Seidl and Barthel (2017).

In the afore-mentioned issue of Nature, Viseu (2015) reports her experiences as a social scientist working for a natural science research organisation. She concludes that social scientists in collaboration with natural scientists often only play "service roles". This is most probably a subjective view, however, it seems in line with our own personal experiences (hence, also based on anecdotal evidence) of collaboration between the fields. As scientists, however, we want to be able to rely on facts and numbers. We decided to explore this quantitatively using groundwater research, a field we know relatively well, as a case study. Water in general, and groundwater in particular, represent excellent candidates for collaborative research activities as the scientific aspects of groundwater range from purely physical, chemical and biological to economic, political, social and cultural. Where, if not here, should interdisciplinarity flourish?

The reader may have noted that the term "interdisciplinarity" was used for the first time in the last sentence, avoiding the need to explain earlier the distinction between related terms such as multi-, cross-or trans-disciplinary or disciplinarity. There is some, yet no clear agreement that crossdisciplinary means the least intensive and inter-disciplinary means the most intensive form of collaboration, and that multidisciplinarity lies somewhere in-between. Some use trans-disciplinarity as a synonym for interdisciplinarity, while 
others describe it as a concept of integrating non-scientists in planning and performing research (e.g., Pohl 2011). In the context of the results reported in the next section, it is important to note the distinction between inter- and multidisciplinarity made in Barthel and Seidl (2017) and Seidl and Barthel (2017), where multi-disciplinary collaboration is regarded as any form of collaboration between scientific disciplines (in parallel, sequentially), while interdisciplinary collaboration is seen as a truly collaborative joint research effort. Note that the quantitative measurements performed in Barthel and Seidl (2017) can, at best, detect and quantify multi-disciplinarity. A clarification is also needed as to what is understood as "social sciences" in the context of those measurements. A simplistic approach was used here in referring to social sciences; every discipline that does not belong to the natural sciences or engineering is social science. This way, economics (and all of its subspecialisations), administration, law and psychology, as well as arts and humanities, are here combined into social sciences, with the awareness that some economists or psychologists would object.

We performed our quantitative measurement of multidisciplinary collaboration between natural and social sciences in groundwater research on a confined body of journal articles from a selection of 12 journals. To be included in our selection, the articles had to have "groundwater" in the title, and at least one typical "social science keyword" in the keywords section. In our final selection of 203 research articles, we looked at the disciplinary composition of author teams, the disciplines of cited references, and the assessed articles' titles and keywords. Finally, we looked at the content of the articles identified as potentially being the result of a collaboration between natural and social scientists. The full methodology, results and the data used are published in Barthel and Seidl (2017). Here we would like to summarise some key findings with potential relevance for the readers of Hydrogeology Journal.

Firstly, we found that interdisciplinarity (and related terms) is much more frequently mentioned in today's articles than 50 years ago (an increase roughly by a factor of 10). In this respect, groundwater research does not differ from other fields of research. Secondly, we noticed a drastic increase of "social science keywords" in groundwater-related articles. While 50 years ago only $2 \%$ of these articles used terms such as "governance", "cost benefit analysis", "eco-system services" or simply "management" to characterise their contents, today it is about $30 \%$. As we had contained our detailed analysis from 1990 to 2014, we cannot say what the percentage of social science groundwater papers was 50 years ago, but at least within the elected block (1990-2014), it remained rather stable at around $5 \%$. For this period, we found that the overall percentage of multidisciplinary articles, combining natural and social science aspects, was low, in the single-digit range (1-2\%), with little significant increase. It seems, thus, that neither the increased mentioning of "interdisciplinarity" nor the more frequent use of social science keywords in groundwater articles are reflected in the way research is actually done. It appears as if authors seem to feel a strong need to express that their studies are somehow related to interdisciplinarity, or have some links to societal aspects, yet without empirically demonstrating this. A typical example regards the articles describing modelling studies. Here, it is quite common to mention the societal contexts that a model is supposed to be used for, while the article itself merely focuses on its technical aspects.

We also observed that high impact water journals such as Water Resources Research show a decreasing trend with respect to the number of social science and multidisciplinary articles. Presently, such articles are more frequently found in journals of much lower impacts such as Water International (if one accepts that impact can be expressed through number of citations). Related to this, we found that multidisciplinary articles receive considerably less citations than disciplinary ones, and natural science articles receive more than social science. This may seem natural, given the different sizes of the respective groups of researchers. What is worrying though, is that the (perceived) need for high impact factors and h-index values for scientific career advancement results in less incentives for conducting interdisciplinary research.

Although we had not included Hydrogeology Journal in our detailed analysis, we used some of its recent issues for a quick, qualitative "validation". We suggest that the interested reader takes a look at a random selection of say 100 articles and will quite likely find that the number dealing with social science aspects of groundwater in Hydrogeology Journal is very low. This can be deduced just by looking at the titles and keywords. For those few, where the title and keywords suggests social science contents, a deeper look into the text, however, often reveals that the actual content is less social science orientated than initially expected. Collaboration between the natural and social sciences is harder to detect by looking at titles and keywords only, but we feel very safe claiming that only very few articles in Hydrogeology Journal are a result of such collaborations, and/or describe only limited aspects outside the multidisciplinary context. In that regard, it should also be mentioned that there is a difference between "multi-disciplinary journals" (e.g. Nature), i.e. journals publishing contributions from different disciplines, and journals that publish multi-disciplinary articles. Hydrogeology Journal has previously published theme issues and topical collections (e.g., Social and Economic Aspects of Groundwater Governance, Volume 14, Issue 3, March 2006) which clearly belong to the fields of social science but does not necessarily contain articles which result from multi-disciplinary collaboration.

It is also interesting to look at which authors are involved in writing the articles that combine natural and social science aspects of groundwater. While mixed teams consisting of 
clearly identifiable natural and social scientists do occur, individuals with multidisciplinary backgrounds or from disciplines located at the natural-social interface (e.g. geography, planning and management etc.) hold a large share of the authorship. In those cases, where collaboration occurs between scientists from two separate fields (clearly classifiable as belonging to a discipline), social sciences are most often represented by economists (70\%); a trend which is increasing over time. Other authors have explained this as being due to the more quantitative nature of economics, which is easier for natural scientists to comprehend (e.g., Phillipson and Lowe 2006).

When initially planning our study, we had also hoped to learn something about the nature of collaboration between the natural and social sciences, e.g. if the activities are "just" multi-disciplinary or truly inter-disciplinary. However, even in those few articles which clearly combined natural and social sciences we found hardly any description of how collaboration was performed. Our (cautious) interpretation is that journal articles might not be an appropriate platform to describe such things. A truly interdisciplinary research endeavour may not necessarily result in interdisciplinary articles due to length restrictions, mono-disciplinarily trained reviewers and authors' career considerations (see the preceding); it may very well lead to the publication of small disciplinary snippets, rather than the large interdisciplinary picture. In particular, peer review might form a bottleneck: competent reviewers for cross-over articles are hard to find, and novelty and originality of interdisciplinary research hard to understand for disciplinarily trained evaluators.

\section{Conclusions}

While scientists increasingly talk about the need for collaboration between natural and social scientists (both in research in general, as well as in groundwater research), it is observed that this collaboration is not increasing very much, and is even decreasingly published in mainstream water journals. Most likely, that does not mean that collaboration does not take place, but that the respective results are published by other journals with lower impact, or not in journals at all. The literature on interdisciplinarity provides some explanations relating to a lack of reviewers with interdisciplinary training, as well as the assumed negative possible impacts on the career options of young scientists among others (e.g., Carayol and Nguyen Thi 2005; Rylance 2015).

Closing the loop to the afore-mentioned editorial in Nature, all this leaves us with the following questions to consider: Are we not contributing "to solving the grand challenges facing society" with interdisciplinary research to the extent we should? Or, are scientific journals such as Hydrogeology Journal just not correctly positioned to talk about those contributions? Interdisciplinary journals operate as containers for interdisciplinary research, but are probably undervalued as represented by the impact factor and are less recognised by groundwater researchers. However, as interdisciplinary collaboration at the interface between the natural and social sciences deserves more attention, why not publish more of it in Hydrogeology Journal?

Acknowledgements I would like to thank my colleague Roman Seidl from Environmental Systems Science, Transdisciplinarity Lab, ETH Zurich, Switzerland, who had equally contributed to the studies on which this Editor's Message is based.

\section{References}

Barthel R, Seidl R (2017) Interdisciplinary collaboration between natural and social sciences: status and trends exemplified in groundwater research. PLoS One 12:e0170754. doi:10.1371/journal.pone. 0170754

Carayol N, Nguyen Thi TU (2005) Why do academic scientists engage in interdisciplinary research? Res Eval 14:70-79

Nature (2015) Why interdisciplinary research matters. Nature 525:305. doi:10.1038/525305a

Phillipson J, Lowe P (2006) Special issue guest editorial: the scoping of an interdisciplinary research agenda. J Agric Econ 57:163-164. doi: 10.1111/j.1477-9552.2006.00044.x

Pohl C (2011) What is progress in transdisciplinary research? Futures 43: 618-626. doi:10.1016/j.futures.2011.03.001

Rylance R (2015) Grant giving: global funders to focus on interdisciplinarity. Nature 525:313-315. doi:10.1038/525313a

Seidl R, Barthel R (2017) Linking scientific disciplines: hydrology and social sciences. J Hydrol. doi: 10.1016/j.jhydrol.2017.05.008

Sivapalan M, Savenije HHG, Bloschl G (2012) Socio-hydrology: a new science of people and water. Hydrol Process 26:1270-1276. doi:10. 1002/hyp.8426

Viseu A (2015) Integration of social science into research is crucial. Nature 525:291 